\title{
Construction of Indium Oxide/N-Doped Titanium Dioxide Hybrid Photocatalysts for Efficient and Selective Oxidation of Cyclohexane to Cyclohexanone
}

Kuan Wang, ${ }^{* \dagger}$ Bing Xue,${ }^{\dagger}$ Jun-Lei Wang, ${ }^{\dagger}$ Zhen-Hong He, ${ }^{\dagger}$ Song-Song Li,${ }^{\dagger}$ Dan Wang, ${ }^{\dagger}$ Wei-

Tao Wang, ${ }^{\dagger}$ Yang Yang, ${ }^{\dagger}$ Zhao-Tie Liu ${ }^{*},{ }^{\dagger}, \dagger$

†Shaanxi Key Laboratory of Chemical Additives for Industry, College of Chemistry and Chemical Engineering, Shaanxi University of Science and Technology, Xi'an, 710021, China

' School of Chemistry \& Chemical Engineering, Shaanxi Normal University, Xi'an, 710119, China

*Corresponding authors. E-mail addresses: wangkuan@sust.edu.cn (K. Wang), ztliu@snnu.edu.cn (Z.-T. Liu).

\section{Materials}

Indium (III) nitrate hydrate $\left(\mathrm{In}\left(\mathrm{NO}_{3}\right)_{3} \cdot \mathrm{H}_{2} \mathrm{O}, 99.99 \%\right)$ was obtained from Adamas. Tetrabutyltitanate (TBT, $\left.\mathrm{C}_{16} \mathrm{H}_{36} \mathrm{O}_{4} \mathrm{Ti}, 98.0 \%\right)$ and absolute ethyl alcohol $\left(\mathrm{CH}_{3} \mathrm{CH}_{2} \mathrm{OH}\right.$, AR) were purchased from Macklin. Anatase $\mathrm{TiO}_{2}$ (99\%) and CHA (99.5\%) were obtained from Aladdin. Urea $\left(\mathrm{CO}\left(\mathrm{NH}_{2}\right)_{2}, 99 \%\right)$ was purchased from Tianjin Damao Chemicals Co., Ltd., China. Melamine $\left(\mathrm{C}_{3} \mathrm{~N}_{3}\left(\mathrm{NH}_{2}\right)_{3}, 99 \%\right)$ was purchased from InnoChem Co., Ltd., China. Oxygen gas $\left(\mathrm{O}_{2}, 99.99 \%\right)$ was obtained from Xi'an Teda Cryogenic Equipment Co., Ltd. 
GC and GC-MS spectra for the reaction
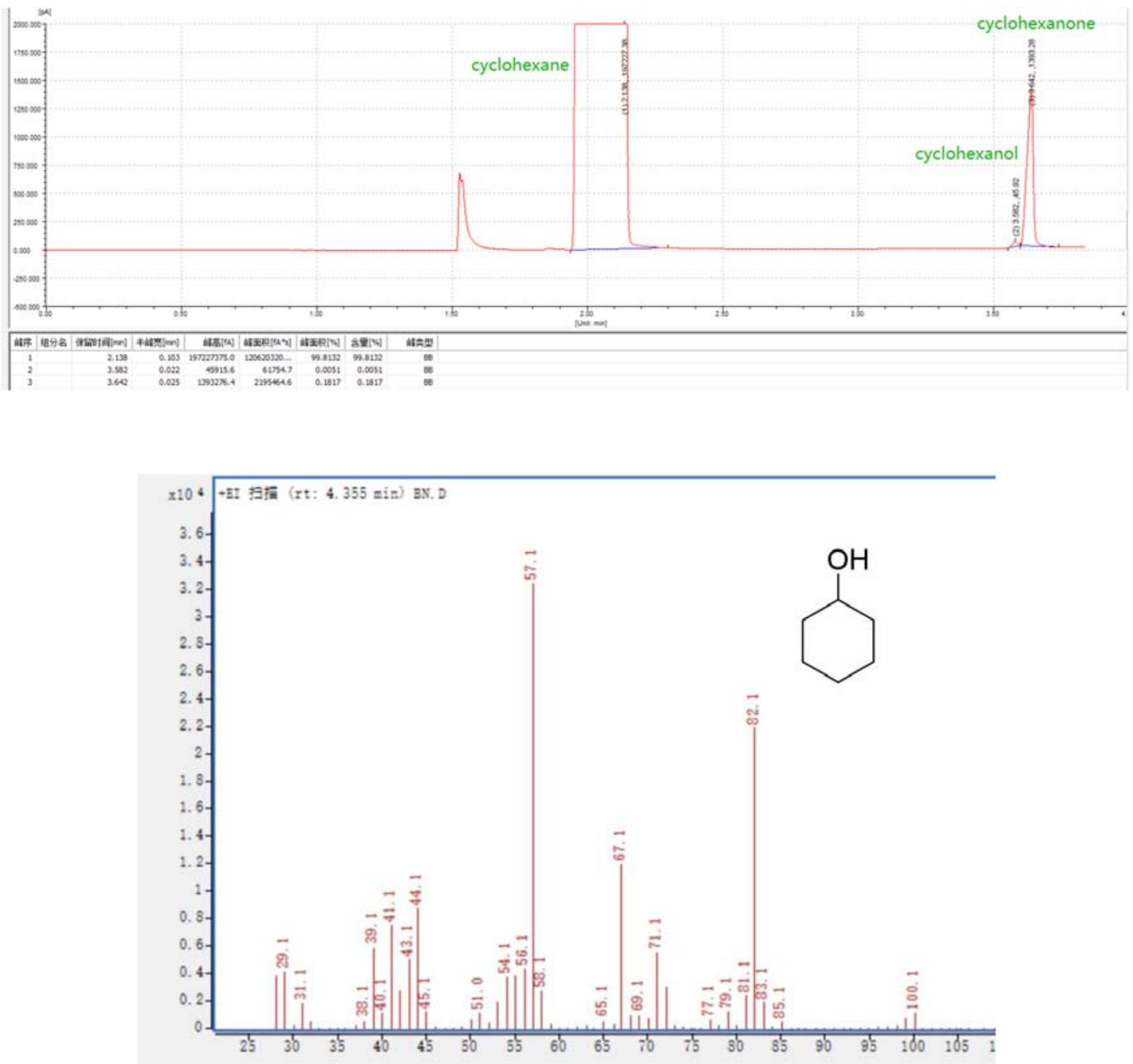

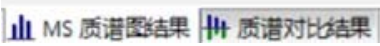




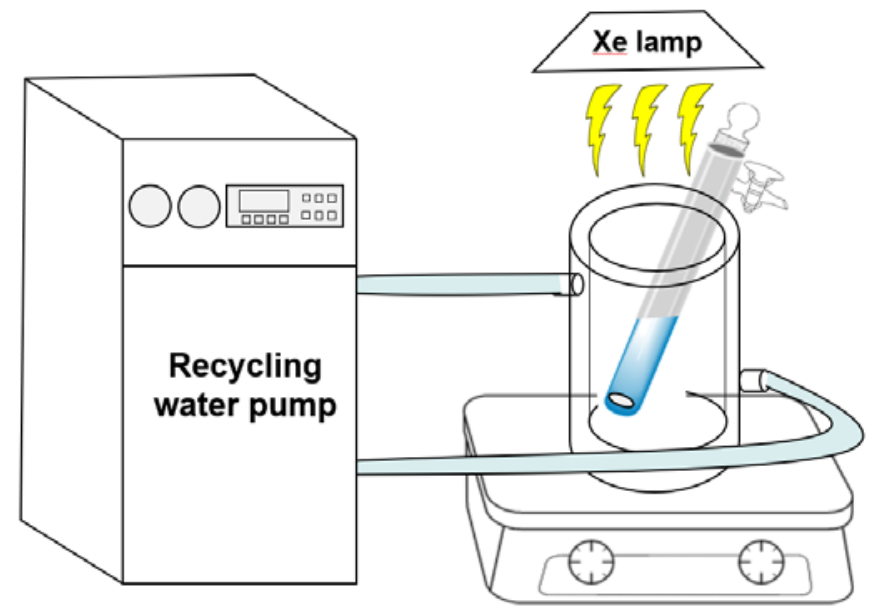

Figure S1. The schematic of the reaction device. 
(a)

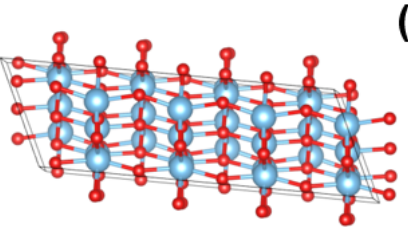

(d)

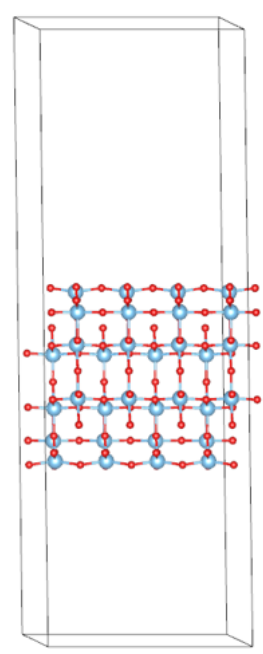

(b)

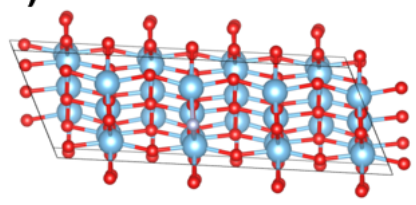

(e)

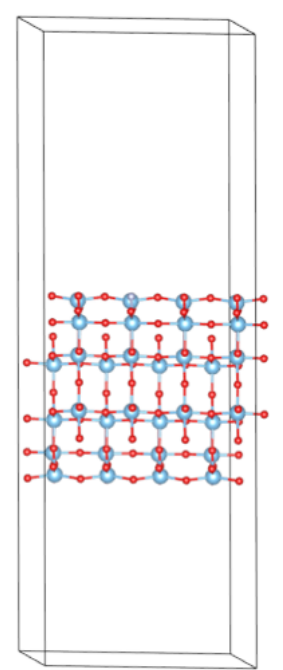

(c)

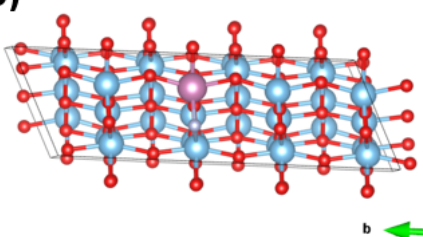

(f)

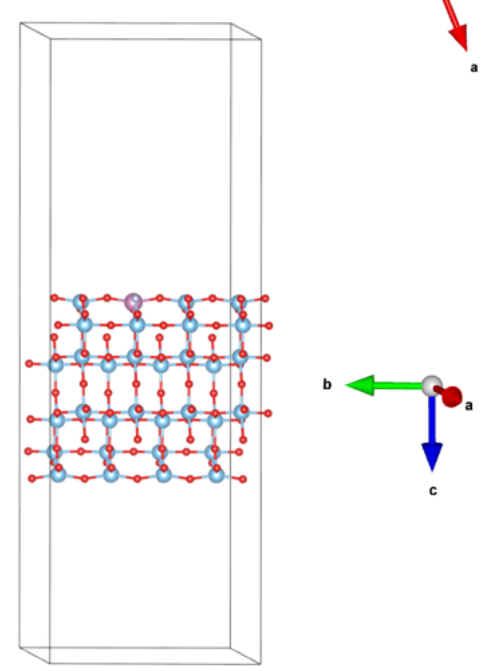

Figure S2. The structures of (a, d) $\mathrm{TiO}_{2}$ slab model, (b, e) N-doped $\mathrm{TiO}_{2}$ slab model, and (c, f) In and $\mathrm{N}$-doped $\mathrm{TiO}_{2}$ slab model. 


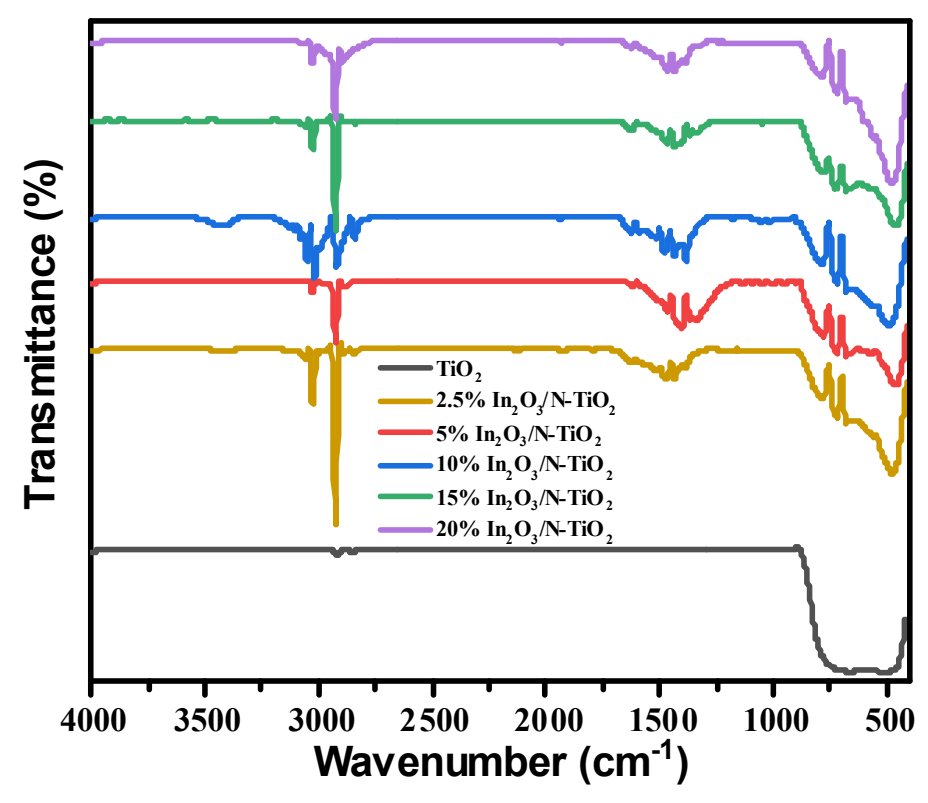

Figure S3. FT-IR spectra of pure $\mathrm{TiO}_{2}$ and $\mathrm{x} \% \mathrm{In}_{2} \mathrm{O}_{3} / \mathrm{N}-\mathrm{TiO}_{2}$ catalysts. 

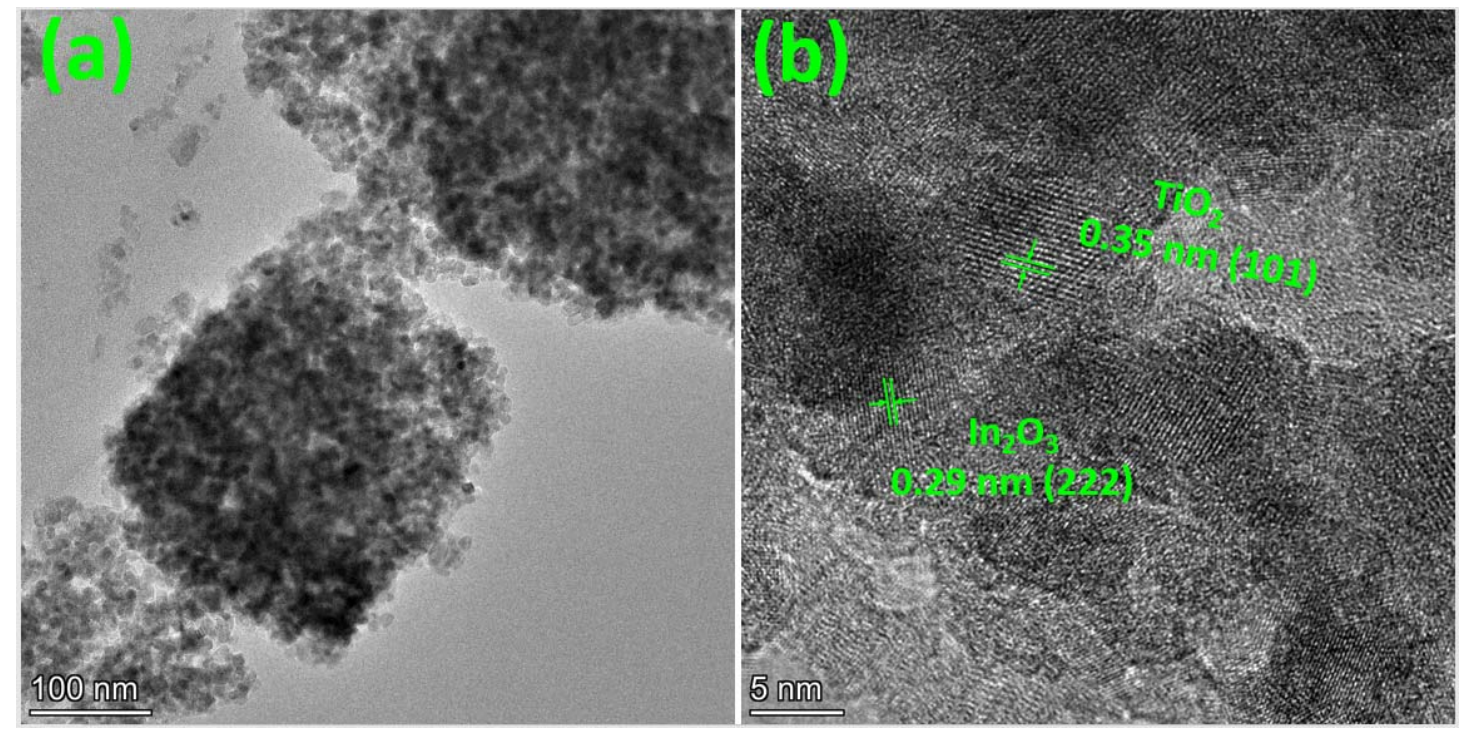

Figure S4. TEM images (a), HRTEM images (b) of $5 \% \mathrm{In}_{2} \mathrm{O}_{3} / \mathrm{N}-\mathrm{TiO}_{2}$ hybrid catalyst after reaction. 

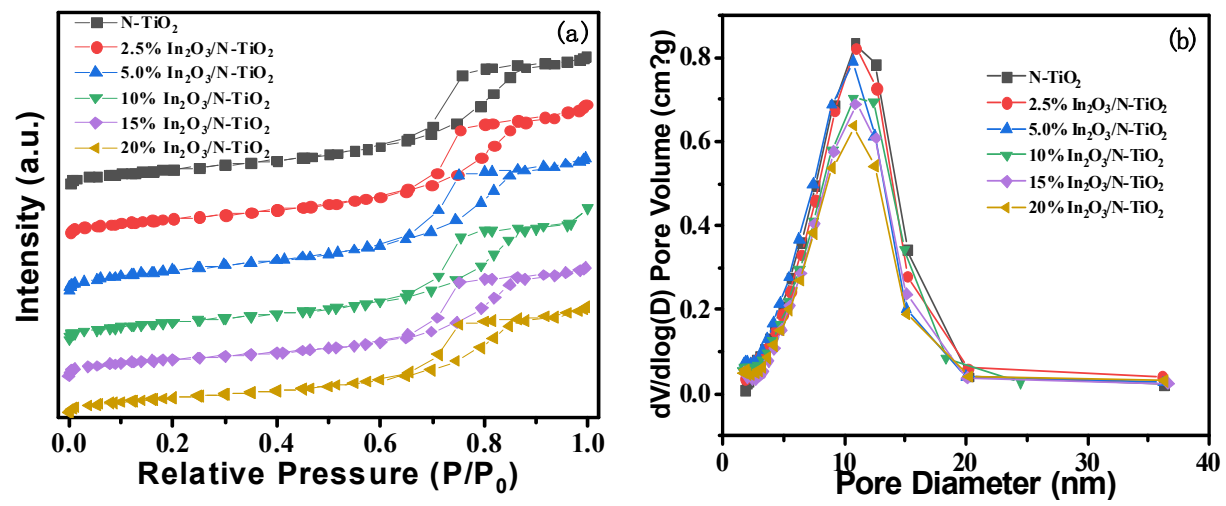

Figure S5. (a) $\mathrm{N}_{2}$-adsorption-desorption isotherms and (b) pore size distribution curves of the obtained catalysts 


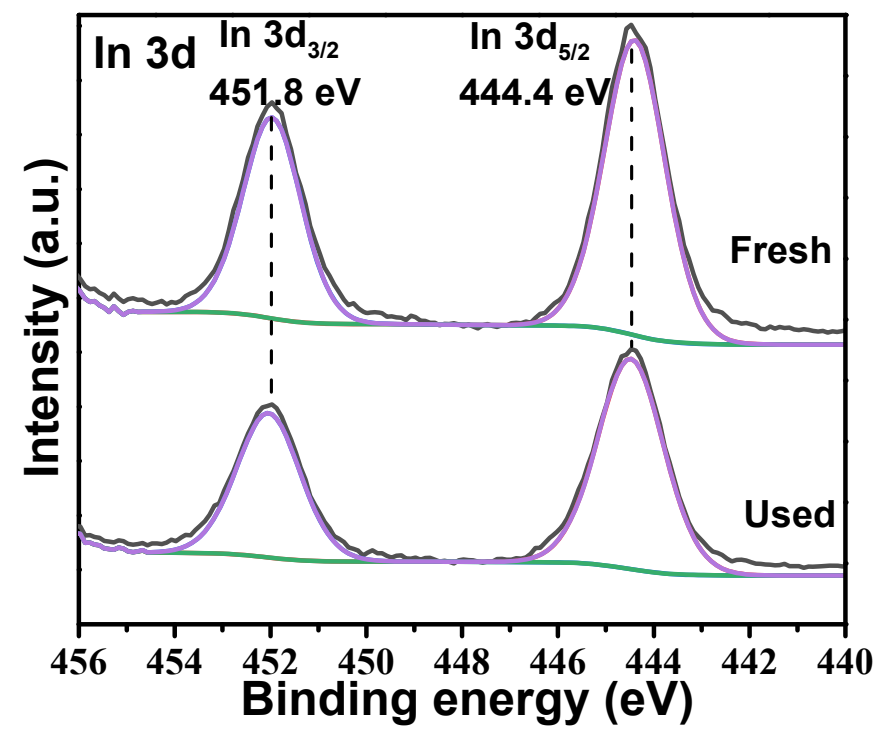

Figure S6. XPS spectra of In $3 \mathrm{~d}$ of $5 \% \mathrm{In}_{2} \mathrm{O}_{3} / \mathrm{N}-\mathrm{TiO}_{2}$ before and after photocatalytic reaction. 


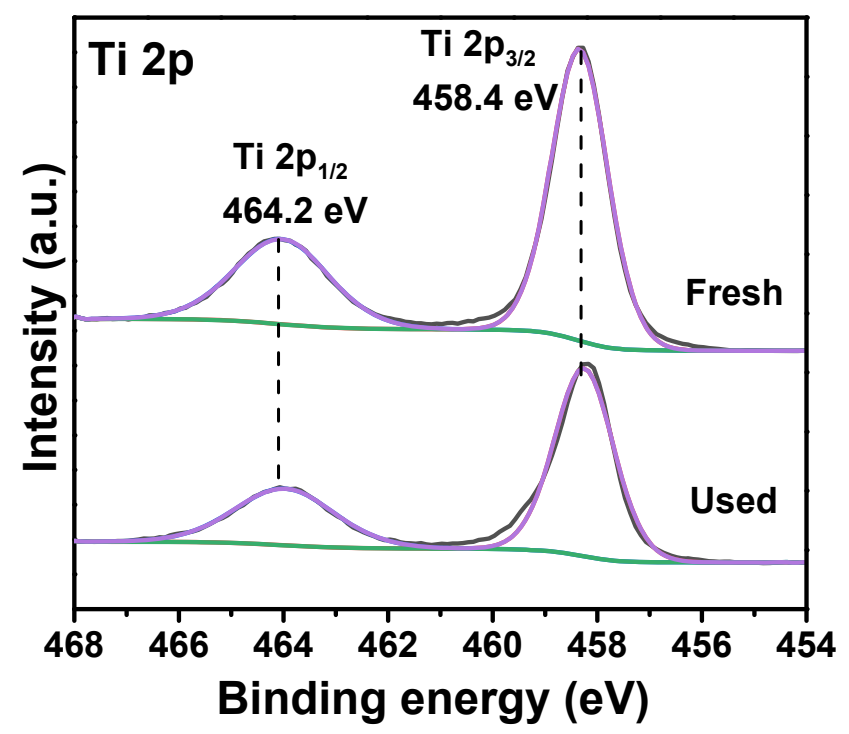

Figure S7. XPS spectra of Ti $2 \mathrm{p}$ of $5 \% \mathrm{In}_{2} \mathrm{O}_{3} / \mathrm{N}-\mathrm{TiO}_{2}$ before and after photocatalytic reaction. 


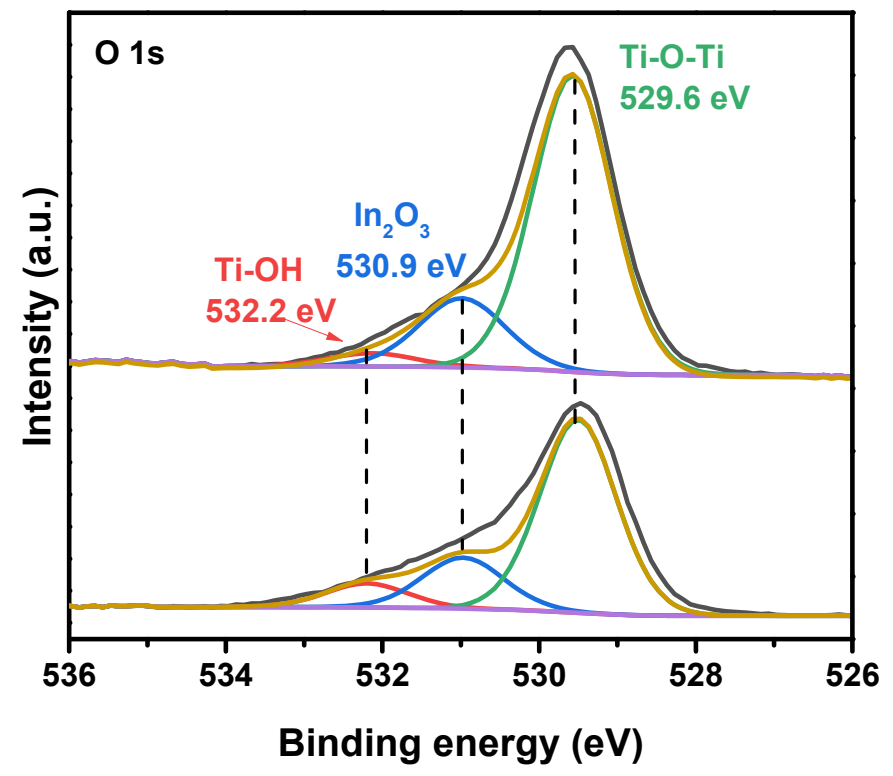

Figure S8. XPS spectra of $\mathrm{O} 1 \mathrm{~s}$ of $5 \% \mathrm{In}_{2} \mathrm{O}_{3} / \mathrm{N}-\mathrm{TiO}_{2}$ before and after photocatalytic reaction. 


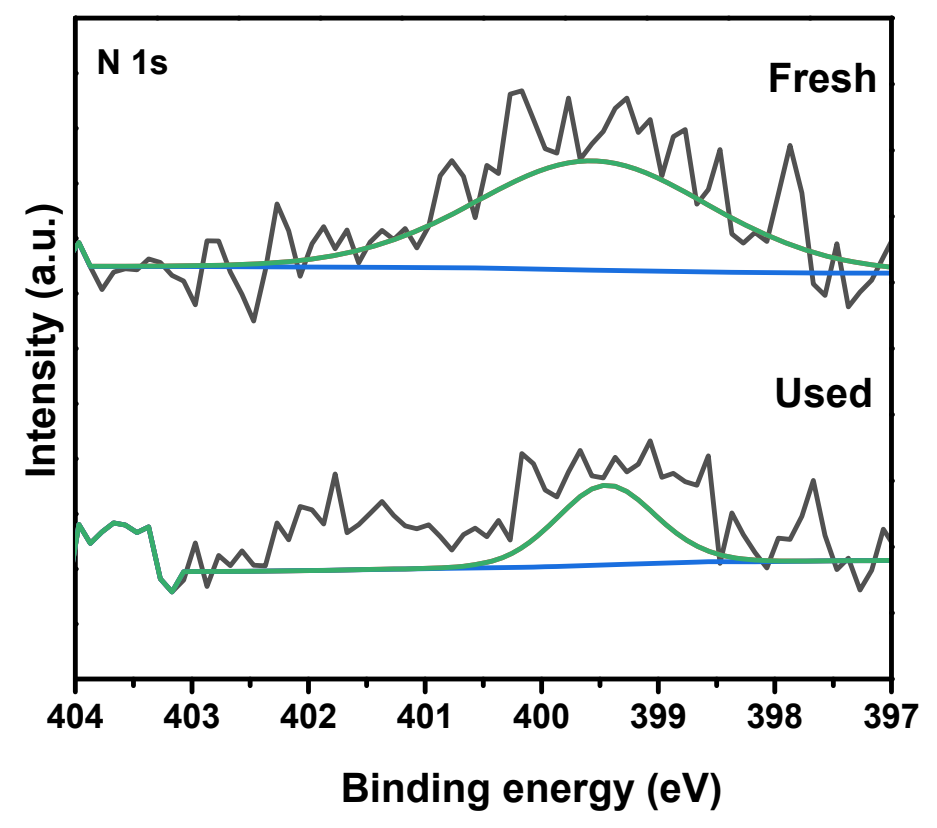

Figure S9. XPS spectra of $\mathrm{N} 1 \mathrm{~s}$ of $5 \% \mathrm{In}_{2} \mathrm{O}_{3} / \mathrm{N}-\mathrm{TiO}_{2}$ before and after photocatalytic reaction. 